\title{
Real-time attentional models for classical conditioning and the hippocampus
}

\author{
NESTOR A. SCHMAJUK and JOHN W. MOORE \\ University of Massachusetts, Amherst, Massachusetts
}

\begin{abstract}
Moore and Stickney (1980) described a real-time computational version of Mackintosh's (1975) attentional model of associative learning. By assuming that hippocampal lesions affect computations that control the rate of learning, they were able to simulate impairments of latent inhibition and blocking, as reported in studies of classical conditioning. Schmajuk (1984a) proposed that hippocampal lesions affect computations of stimulus associabilities, as defined in Pearce and Hall's (1980) model of learning. A revised version of the Moore-Stickney model and a real-time version of Pearce and Hall's (1980) model, both incorporating the proposed modifications for the effect of hippocampal lesions, were applied to different classical conditioning paradigms. Simulation experiments with both models were carried out for the following protocols: acquisition under simultaneous, delay, and trace conditioning; partial reinforcement; noncontingent training; conditioned inhibition; differential conditioning; extinction; latent inhibition; blocking; overshadowing; and discrimination reversal. Although some discrepancies between simulation experiments and relevant literature were noted, both models proved capable of simulating most hippocampal lesion effects.
\end{abstract}

Theories of the role of the hippocampus in learning and memory have related this structure to various psychological processes, for example, attention, chunking, cognitive mapping, contextual retrieval of information from memory, internal inhibition, long-term memory selection, recognition memory, response inhibition, spatial memory, and working memory. Schmajuk (1984b) contrasted predictions of the various theories with reproducible hippocampal lesion data. Attentional theories were among those most consistent with lesion data from a variety of experimental paradigms.

Attentional theories have received different treatments by different authors, evolving from relatively simple verbal descriptions to highly elaborate mathematical models. Grastyan, Lissak, Madarasz, and Donhoffer (1959) were among the first to implicate the hippocampus in attentional processes. Stated simply, they proposed that the hippocampus inhibits the orienting response to nonsignificant CSs. Douglas and Pribram (1966) proposed that the hippocampus excludes CSs from attention through efferent control of sensory reception. This control inhibits the reception of CSs that have been associated with nonreinforcement. In a related view, Kimble (1968) proposed that the hippocampus enables the organism to uncouple its attention from one CS and shift its attention to new and more

\footnotetext{
This study was supported in part by a fellowship to the first author based on NSF Grant IST8417756 and by AFORS Grant 83-0215 to the second author. N. A. Schmajuk's present address is: Center for Adaptive Systems, Department of Mathematics, Boston University, Boston, MA 02215. J. W. Moore's mailing address is: Department of Psychology, University of Massachusetts, Amherst, MA 01003.
}

consequential environmental events. Douglas (1972) proposed yet another version of the Douglas and Pribram theory, one in which the hippocampus correlates a CS with nonreinforcement, thereby reducing its attentional priority. These three theories share the idea that the hippocampus is the organ of internal inhibition, and they all relate internal inhibition to an attentional mechanism. Pribram and Isaacson (1975) suggested that the hippocampus computes the probability that some behavior would proceed to completion. If this probability were high, the animal would not alter its behavior. If it were low, for example because some novelty had been detected, a behavioral shift involving attentional and response changes would be produced. Solomon and Moore (1975; Solomon, 1977, 1979) hypothesized that the hippocampus participates in the "tuning out" of CSs poorly associated with reinforcement. This view is closely related to Douglas's (1972), but for Douglas the hippocampus attenuates the reception of a nonreinforced CS, whereas for Solomon and Moore (1975) it attenuates the processing of CSs that are irrelevant to the task at hand. Moore (1979a) proposed a neuronal model to explain how the hippocampus might participate in "tuning out" during conditioning of the rabbit's nictitating membrane (NM) response.

The verbal nature of most of the theories precludes unequivocal predictions of the outcome of many experimental paradigms, suggesting the need for formal models that provide a rigorous framework in which to describe behavior in tasks sensitive to hippocampal dysfunction. Moore and Stickney (1980) proposed a mathematical model (M-S) of the hippocampal function based on Mac- 
kintosh's (1975) attentional theory. In its simplest form, the model can be represented by an equation that describes the variation of the associative strength $(\mathrm{V})$ between the CS and the US: $\Delta \mathrm{V}=\mathrm{k} \alpha(1-\mathrm{V})$, where $\alpha$ is the attentional factor representing the associability or salience of the CS $(0<\alpha \leq 1)$ and $\mathrm{k}$ is a constant $(0<\mathrm{k} \leq 1)$. Whenever CS(A) is a better predictor of the outcome of the trial than another stimulus $(X)$ present at the same time, $\alpha_{\mathrm{A}}$ is increased by $\Delta \alpha_{\mathrm{A}}=\mathrm{c}\left(1-\alpha_{\mathrm{A}}\right)\left(\mathrm{V}_{\mathrm{A}}-\mathrm{V}_{\mathrm{X}}\right)$. Otherwise, $\alpha_{\mathrm{A}}$ is decreased by $\Delta \alpha_{\mathrm{A}}=-c \alpha_{\mathrm{A}}\left(\mathrm{V}_{\mathrm{X}}-\mathrm{V}_{\mathrm{A}}\right)$, where $V_{X}$ is the higher associative value, and where $c$ is a constant, $0<\mathrm{c} \leq 1$. According to Moore and Stickney (1980), the hippocampus carries out the second computation. Thus, hippocampal lesions (HL) prevent $\alpha$ from decreasing. Computer simulations of the M-S model (Moore \& Stickney, 1980, 1982) showed that the model simulates the behavior of HL animals in latent inhibition (LI), blocking, and spatial learning.

Schmajuk (1984a) suggested that Pearce and Hall's (1980) model of learning (P-H) might also serve as a framework for describing attentional deficits in HL animals. The modified and extended version of the P-H model described in this paper is labeled the S-P-H model. In the S-P-H model, as in the M-S model, changes in CS-US associations depend on the CS's associability. In the normal case, the associability of a CS depends on predictions of the US made by all the CSs acting at that moment and on its associability on previous occasions. In the HL case, the associability of a CS is dissociated from other CSs; it depends neither on predictions of the US by other CSs nor on its associability on prior occasions.

The present paper compares computer simulations of the M-S and the S-P-H models with experimental data obtained from normal and HL animals trained in various classical conditioning paradigms and protocols.

\section{Moore and Stickney (M-S) Model}

The M-S model has undergone several refinements since its first application to the problem of describing the role of the hippocampus in classical conditioning (see Moore \& Stickney, 1980, 1982, 1985). Even in its most recent version (Moore \& Stickney, 1985), the M-S model does not accurately portray the effects of partial reinforcement, differential conditioning, and extinction. Problems are caused by the algorithms generating antiassociations, which were modified in the version presented in this paper. The following summarizes the present rendering of the model: (1) Associative value, V, represents the prediction of the US (appetitive or aversive) by a CS. (2) Antiassociative value, N, represents the prediction of nonreinforcement by a CS. (3) The strength of a CR elicited by a CS depends on its net associative value, $\dot{V}$, given by $\mathrm{V}-\mathrm{N}$. (4) $\mathrm{V}$ for a given CS increases when it accurately predicts the US. V decreases whenever the US does not occur and the sum of $\dot{V}$ s of all the CSs acting on a given trial is greater than zero. (5) By contrast, $\mathrm{N}$ increases whenever the US does not occur and the sum of Vs of all the CSs acting on a given trial is greater than zero. $\mathrm{N}$ decreases whenever the US follows the CS. (6) The rate of change of $\mathrm{V}$ and $\mathrm{N}$ depends on the associability, $\alpha$, of the CS. (7) $\alpha$ increases whenever the CS is the best predictor of the US and other stimuli (including itself) in the situation. Otherwise it decreases. A given CS is considered the best predictor of the US when it has the highest $V$ value of all present CSs. (8) The dependence of $\alpha$ on the predictive associative relationships among all stimuli in the situation implies the existence of a network in which each CS is associated with itself, with the other CSs, and with the US. (9) The model applies to real time, implying that computations occur continuously within and between trials.

\section{Formal Statement of the M-S Model}

The model incorporates two types of association: (1) the association whereby a CS predicts that an event (the CS itself, another CS, or the US) will occur, and (2) the association whereby the CS predicts that an event will not occur, that is, the antiassociation. Association and antiassociation are represented by $\mathrm{V}$ and $\mathrm{N}$, respectively.

Associations. When a $\mathrm{CS}_{\mathrm{i}}$ is accompanied or followed by the $\mathrm{k}^{\text {th }}$ event, the change in the associative value, $V_{i}^{k}$, between the CS and event $\mathrm{k}$, is increased by

$$
\Delta \mathrm{V}_{\mathrm{i}}^{\mathrm{k}}=\alpha_{\mathrm{i}} \theta \tau\left(1-\mathrm{V}_{\mathrm{i}}^{\mathrm{k}}\right) .
$$

When the event $k$ does not occur, $V_{i}^{k}$ is decreased by

$$
\Delta \mathrm{V}_{\mathrm{i}}^{\mathrm{k}}=\alpha_{\mathrm{i}} \theta^{\prime} \tau\left(0-\mathrm{V}_{\mathrm{i}}^{\mathrm{k}}\right)\left(\Sigma \mathrm{V}_{\mathrm{j}}^{\mathrm{k}}-\Sigma \mathrm{N}_{\mathrm{j}}^{\mathrm{k}}\right),
$$

where $\Sigma V_{j}^{k}-\Sigma_{j}^{k}$ is the difference between the sums of associative and antiassociative values of all stimuli with index $\mathrm{j}$ present at that moment, including $\mathrm{i}$. It should be noted that $\lambda$ in Mackintosh's model has been replaced by 1 or 0 , and therefore variable $\mathrm{V}$ ranges between 0 and 1 by Equations 1 and $2 . \dot{V}_{i}^{k}$ is interpreted as the degree of "belief" that $\mathrm{CS}_{\mathrm{i}}$ is followed by event $\mathrm{k}$, and this belief is placed on a scale of 0 to 1 to be isomorphic with probabilities. Events differing only in their intensities, implying different $\lambda s$ in Mackintosh's (1975) model, are seen in the M-S model as different events.

The parameter $\alpha_{\mathrm{i}}$ is the associability of the $\mathrm{i}^{\text {th }} \mathrm{CS}$; it ranges between 0 and 1 . The parameter $\theta(0<\theta \leq 1)$ is the rate of change in the association when the reinforcer is presented, and $\theta^{\prime}$ is the rate-of-change constant of the association when the reinforcer is not presented, such that $0<\theta^{\prime}<\theta$.

Temporal properties. The function $\tau$ is defined as

$$
\tau=\operatorname{exp~k}(\mathrm{q}-\Delta \mathrm{t}),
$$

where $\Delta t>0$ is the interval between the $i^{\text {th }}$ event and the $\mathrm{k}^{\text {th }}$ event, $\mathrm{q}$ is a constant equal to the optimal interval for association, and $\mathrm{k}$ is a constant $(0<\mathrm{k} \leq 1)$.

Antiassociations. Whenever a $\mathrm{CS}_{\mathrm{i}}$ is not followed by an event $\mathrm{k}$, the antiassociative value, $\mathrm{N}_{\mathrm{i}}^{\mathrm{k}}$, is increased by

$$
\Delta \mathrm{N}_{\mathrm{i}}^{\mathrm{k}}=\alpha_{\mathrm{i}} \theta^{\prime} \tau\left(1-\mathrm{N}_{\mathrm{i}}^{\mathrm{k}}\right)\left(\Sigma \mathrm{V}_{\mathrm{j}}^{\mathrm{k}}-\sum \mathrm{N}_{\mathrm{j}}^{\mathrm{k}}\right) .
$$

This change allows $N$ to increase whenever $\Sigma N_{j}^{k}<\Sigma V_{j}^{k}$. 
Whenever the event $\mathrm{k}$ follows $\mathrm{CS}_{\mathrm{i}}$, the antiassociative value, $\mathrm{N}_{\mathrm{i}}^{\mathrm{k}}$, is decreased by

$$
\Delta \mathrm{N}_{\mathrm{i}}^{\mathrm{k}}=\alpha_{\mathrm{i}} \theta \tau\left(0-\mathrm{N}_{\mathrm{i}}^{\mathrm{k}}\right) .
$$

The parameters in Equations 4 and 5 are the same as those in Equations 1 and 2. The parameter $\theta$ is used when a $C S_{i}$ is followed by an event $k$ in order to increase $V_{i}^{k}$ and to decrease $N_{i}^{k}$. The parameter $\theta^{\prime}$ is used when a $C S_{i}$ is not followed by an event $k$ in order to decrease $V_{i}^{k}$ and to increase $\mathrm{N}_{\mathrm{i}}^{\mathrm{k}}$. Therefore, $\theta$ determines increments in $\dot{\mathrm{V}}_{\mathrm{i}}^{\mathrm{k}}$ and $\theta^{\prime}$ determines decrements in $\dot{\mathrm{V}}_{\mathrm{i}}^{\mathrm{k}}$.

The net associative value of $\mathrm{CS}_{\mathrm{i}}$ is

$$
\dot{\mathrm{V}}_{\mathrm{i}}^{\mathrm{k}}=\mathrm{V}_{\mathrm{i}}^{\mathrm{k}}-\mathrm{N}_{\mathrm{i}}^{\mathrm{k}} \text {. }
$$

Changes in associability of stimuli. The associability cf CS $\mathrm{C}_{\mathrm{i}}, \alpha_{\mathrm{i}}$, may increase, decrease, or remain unchanged azcording to a weighted combination of event-specific components. These event-specific components are computed on the basis of the relationship between the associative value of $\mathrm{CS}_{\mathrm{i}}$ and the event $\mathrm{k}$ and the associative value of another $\mathrm{CS}_{\mathrm{j}}$ with the same event $\mathrm{k}$.

When and only when $\mathrm{CS}_{\mathrm{i}}, \mathrm{CS}_{\mathrm{j}}$, and event $\mathrm{k}$ are presented together, and provided $V_{i}^{k}>V_{j}^{k}$,

$$
\Delta \alpha_{i}^{k}=c\left(1-\alpha_{i}\right)\left(V_{i}^{k}-V_{j}^{k}\right),
$$

where $V_{j}^{k}$ is the second highest associative value with respect to the event $k$ of all the CSs present with the $\mathrm{CS}_{\mathrm{i}}$, including the context.

If $\mathrm{V}_{\mathrm{j}}^{\mathrm{k}} \geq \mathrm{V}_{\mathrm{i}}^{\mathrm{k}}$,

$$
\Delta \alpha_{\mathrm{i}}^{\mathrm{k}}=\mathrm{c}\left(0-\alpha_{\mathrm{i}}\right)\left(\mathrm{V}_{\mathrm{j}}^{\mathrm{k}}-\mathrm{V}_{\mathrm{i}}^{\mathrm{k}}\right),
$$

where $V_{j}^{k}$ is the highest associative value with respect to $\mathrm{k}$ of all the CSs present with $\mathrm{CS}_{\mathrm{i}}$. The parameter $\mathrm{c}$ in Equations 7 and 8 is set $0<c \leq 1$.

Once the event-specific components of $\Delta \alpha_{i}$ have been computed, they are combined in the expression

$$
\Delta \alpha_{\mathrm{i}}=\sum_{\mathrm{k}} \phi_{\mathrm{k}} \Delta \alpha_{\mathrm{i}}^{\mathrm{k}} / \sum_{\mathrm{h}} \phi_{\mathrm{h}}
$$

The sum over the index $\mathrm{k}$ in the numerator of Equation 9 involves all the events present with the $\mathrm{CS}_{\mathrm{i}}$. The sum over the index $\mathrm{h}$ in the denominator of Equation 9 involves all the events the subject has encountered in previous experiences in the same context, even though they may not be present at the time when $\Delta \alpha_{\mathrm{i}}$ is computed. The US is presumed to be represented in memory more strongly than the other CSs, including the context $(\mathrm{X})$, and therefore weights are usually selected such that $\phi_{\mathrm{US}}>\phi_{\mathrm{CS}}>\phi_{\mathrm{X}}$.

Effects of HL. Moore and Stickney (1980) assigned to the hippocampus the task of decreasing the associability of a CS. Thus, HL renders all the expressions of the form of Equation 8 equal to zero. CSs that would normally lose associability do not do so, and consequently the animal may not behave appropriately in a given situ- ation. Simulation experiments with the model indicate the set of circumstances in which HL animals would be predicted to differ from normals.

\section{Schmajuk-Pearce-Hall (S-P-H) Model}

Schmajuk (1984a) proposed a model describing the effects of HL on classical conditioning in terms of changes in the computation of the attentional variable defined in Pearce and Hall's (1980) model. Even in its most recent version (Pearce, Kaye, \& Hall, 1982), the P-H model does not accurately portray the effects of partial reinforcement. Problems were caused by the algorithm determining associability, which was modified in the version presented in this paper. This report describes a rendering of the $\mathrm{P}-\mathrm{H}$ model, designated the S-P-H model, that is applicable to real-time simulation experiments. In brief, the S-P-H model makes the following assumptions: (1) Excitatory associative value, $\mathrm{V}$, represents the prediction of the US (appetitive or aversive) by a CS. V increases whenever the CS's associability, $\alpha$, is greater than zero and US intensity on a given trial $(\lambda)$ is larger than that predicted by all the CSs present on that trial. (2) Inhibitory associative value, $\mathrm{N}$, represents the strength of the prediction by a CS that the US will not occur. N increases whenever $\alpha$ is greater than zero and US intensity on a given trial $(\lambda)$ is smaller than or equal to that predicted by all the CSs present on that trial. Like V, N can never decrease. (3) Aggregate net prediction of the US on a given trial, $\Sigma \mathrm{V}_{\mathrm{j}}^{\mathrm{k}}$, as well as CR strength, are given by the difference between $\mathrm{V}$ and $\mathrm{N}$ of all the CSs acting on a trial, $\Sigma \dot{\mathrm{V}}_{\mathrm{j}}$ $=\Sigma\left(\mathrm{V}_{\mathrm{j}}-\mathrm{N}_{\mathrm{j}}\right)$. (4) $\alpha$ for computations of $\mathrm{V}$ and $\mathrm{N}$ for all CSs present on a given trial equals either: (a) the absolute value of the difference between $\lambda$ and $\Sigma \dot{V}_{j}$, both of the current trial, or (b) the geometric mean of the $\alpha \mathrm{s}$ for previous trials (see Kaye \& Pearce, 1984).

\section{Formal Statement of the S-P-H Model}

Changes in excitatory and inhibitory associative value. Whenever the magnitude of the US on a given trial, $\lambda$, is larger than the aggregate prediction of the US made upon all the CSs present on that trial, $V$ of every CS is increased according to

$$
\Delta \mathrm{V}_{\mathrm{i}}=\mathrm{S}_{\mathrm{i}} \alpha_{\mathrm{i}} \beta_{\mathrm{E}} \lambda,
$$

where $S_{i}$ represents $C S_{i}$ salience, $\alpha_{i}$ represents $C S_{i}$ associability, $\beta_{E}$ is the excitatory rate parameter, and $\lambda$ represents the intensity of the US. It can be seen that when $\lambda=0, \Delta \mathrm{V}_{\mathrm{i}}=0$.

Whenever the magnitude of the US on a given trial is less than or equal to the aggregate prediction of the US made by all the CSs present on that trial, $\mathrm{N}$ of every CS is increased by

$$
\Delta \mathrm{N}_{\mathrm{i}}^{\mathrm{k}}=\mathrm{S}_{\mathrm{i}} \alpha_{\mathrm{i}} \beta_{\mathrm{I}} \lambda,
$$

where $\lambda=\Sigma \dot{\mathrm{V}}_{\mathrm{j}}-\lambda ; \beta_{\mathrm{I}}$ is the inhibitory rate parameter. 
Equations 10 and 11 imply that when the reinforcer is not presented $\mathrm{V}$ does not decrease but rather $\mathrm{N}$ increases until it reaches the same value as $\mathrm{V}$. In general, $\beta_{\mathrm{I}}<\beta_{\mathrm{E}} \leq 1$.

The net associative value of $\mathrm{CS}_{\mathrm{i}}$ is

$$
\dot{\mathrm{V}}_{\mathrm{i}}=\mathrm{V}_{\mathrm{i}}-\mathrm{N}_{\mathrm{i}} \text {. }
$$

Changes in associability. In the present version of the $\mathrm{S}-\mathrm{P}-\mathrm{H}$ model, $\alpha_{\mathrm{i}}$ is given by the expression

$$
\alpha_{\mathrm{i}}^{\mathrm{n}}=\gamma\left|\lambda^{\mathrm{n}}-\Sigma \dot{\mathrm{V}}_{\mathrm{j}}^{\mathrm{n}-1}\right|+(1-\gamma) \alpha_{\mathrm{i}}^{\mathrm{n}-1},
$$

where $\gamma$ weights the influence of the absolute difference between the aggregate prediction of the US made upon all the CSs present at a given time $\mathrm{n}$ and the actual value of the US at that time, and $(1-\gamma)$ weights the influence of the associability at time $n-1$ in determining $\alpha_{i}^{n}$. When the US is present, use of Equation 13 is restricted to those cases in which $\alpha_{i}^{n-1}$ is less than $\left|\lambda-\Sigma \dot{V}_{j}^{n-1}\right|$. When $\alpha_{i}^{n-1}$ is larger than $\left|\lambda^{n}-\Sigma V_{j}^{n-1}\right|$, Equation 13 is used with $\gamma=1$. This restriction avoids problems in partial reinforcement paradigms present in the original P-H model (Pearce et al., 1982) and at the same time yields LI. Equation 13 can always be applied when the US is absent.

Temporal properties. A function $\tau$, defined by Equation 3 in the M-S model, is incorporated into the revised version of the $\mathrm{P}-\mathrm{H}$ model in order to allow real-time predictions.

Increments in $V_{i}$ are given by

$$
\Delta \mathrm{V}_{\mathrm{i}}=\mathrm{S}_{\mathrm{i}} \alpha_{\mathrm{i}} \beta_{\mathrm{E}} \tau \lambda
$$

and increments in $\mathrm{N}_{\mathrm{i}}$,

$$
\Delta \mathrm{N}_{\mathrm{i}}=\mathrm{S}_{\mathrm{i}} \alpha_{\mathrm{i}} \beta_{\mathrm{I}} \tau \bar{\lambda} .
$$

Effects of HL. Equation 13 implies that if two CSs (A and $B$ ) are presented together with reinforcement, the associabilities of both decrease to the extent that their combined $\dot{V}$ s predict $\lambda$. In the HL case, we assume, first, that the associability of A and B depends not on their joint prediction of $\lambda$, but on their individual prediction of $\lambda$. Additionally, trial-to-trial (or bin-to-bin) averaging of $\alpha_{\mathrm{i}}$ is disallowed in the HL case. Thus, for a given CS, Equation 13 becomes

$$
\alpha_{\mathrm{i}}=\left|\lambda^{\mathrm{n}}-\dot{\mathrm{V}}_{\mathrm{i}}^{\mathrm{n}-1}\right| .
$$

In addition, for a given CS in the HL case, $\lambda$ in Equation 15 is computed by $\lambda=\dot{\mathrm{V}}_{\mathrm{i}}-\lambda$. Thus, the S-P-H model regards the effect of $\mathrm{HL}$ as an impairment in the integration of new and old predictions about the US arising from all the CSs present at a given time. Therefore, in the HL case, associability of an individual CS is influenced by neither the predictions made by other CSs present on a given trial nor by its own past predictions of the US.

\section{METHOD}

Computer simulation experiments contrasting the predicted behavior of HL and normal cases by the revised M-S and the S-P-H models were carried out under the following procedures: acquisition under $100 \%$ and $50 \%$ reinforcement, truly random or noncon- tingent training such that $\mathrm{P}(\mathrm{US} / \mathrm{CS})=\mathrm{P}(\mathrm{US} /$ noCS $)=.5$, conditioned inhibition, differential conditioning, LI, blocking, overshadowing, and discrimination reversal.

The function $\tau=\operatorname{exp~k}(\mathrm{q}-\Delta \mathrm{t})$ was computed as a function of $\Delta \mathrm{t}$, the interval between CSs and events. $q$ was made equal to $200 \mathrm{msec}$, approximately the optimal interstimulus interval for classical conditioning of the rabbit's nictitating membrane response (Schneiderman \& Gormezano, 1964). A different $q$ should be adopted if one were to simulate a system with a different optimal ISI. For $\Delta t=q$, $\tau=1$. For $\Delta \mathrm{t}=0$ (simultaneous conditioning), $\tau$ was arbitrarily assigned the value 0.067 . For cases in which $\Delta t<0$ (e.g., the US preceding the CS or backward conditioning), $\tau$ was assigned the value 0 . The decay constant of function $\tau$ was set equal to $\mathrm{k}=.1$. Given 12-bin-long trials, this value prevented carryover effects from one trial to the next.

Continuous time, $t$, was converted to discrete time units, or bins (Figure 1). Because bin duration determines the temporal resolution of the simulations, $\mathrm{q}$ is the maximum bin duration that allows simulation of ISIs equal to the optimal interstimulus interval. Consequently, the length of each bin was made equal to $q$, and values of $\Delta t$ in Equation 3 were expressed in units of q. Panels A, B, and
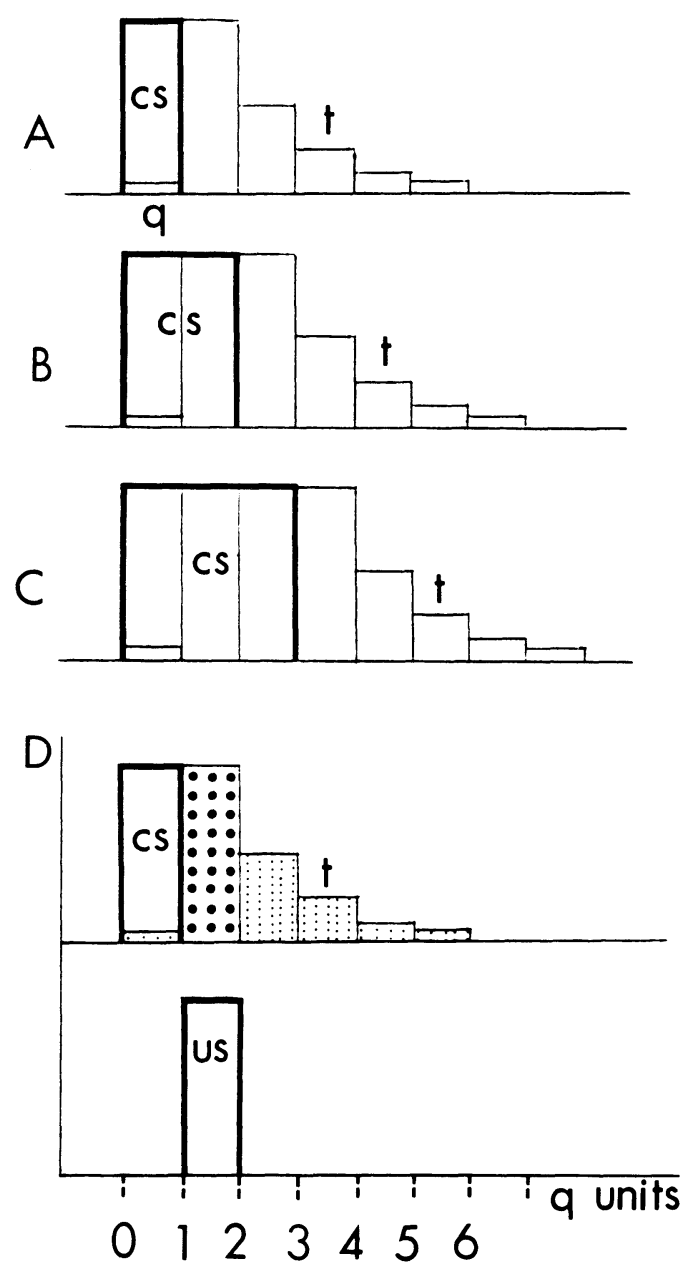

Figure 1. Panels A, B, and C: CSs of 1-, 2-, and 3-bin duration, respectively, and their associated traces, labeled $t$, as computed by Equation 3. Panel D: Large dots indicate the bin in which $V$ increases and $\mathbf{N}$ decreases. Small dots indicate those bins in which $\mathrm{V}$ decreases and $\mathbf{N}$ increases. Time is expressed in $q$ (optimal conditioning interval) units. 
C of Figure 1 show CSs of 1-, 2-, and 3-bin duration, respectively, and their associated traces, labeled $t$, as computed by Equation 3 . Each computation of a change in $\mathrm{V}$ or $\mathrm{N}$ in a bin is proportional to the value of the trace generated by the predictor of an event. If the trace is greater than zero, and the US occurs in that bin, $\mathrm{V}$ increases in both models (and $\mathrm{N}$ decreases in the M-S model); if the US does not occupy that bin, $\mathrm{N}$ increases in both models (and $\mathrm{V}$ decreases only in the M-S model). Panel D of Figure 1 illustrates changes in $\mathrm{V}$ and $\mathrm{N}$ of a CS occupying the 1 st bin and a US occupying the 2 nd bin. Because the US is present in Bin $2, \mathrm{~V}$ increases (and $\mathrm{N}$ decreases in the $\mathrm{M}-\mathrm{S}$ model) at that time. In Bins 1 , $3,4,5$, and 6, where the US is absent, $\mathrm{N}$ increases (and V decreases in the M-S model). If the US occupied Bins 2 and 3, V would increase (and $\mathrm{N}$ would decrease in the M-S model) at that time, and in Bins 1, 4, 5, and 6, where the US would be absent, $\mathrm{N}$ would increase (and V would decrease in the M-S model).

It is apparent from Figure 1D that bin length dictates the resolution of a simulation but not its result. For instance, if $q$ were equal to $100 \mathrm{msec}$ instead of $200 \mathrm{msec}$, both CS and US would double their duration expressed in bins. The number of reinforced and nonreinforced bins would double, but the resulting values of $\mathrm{V}$ and $\mathrm{N}$ would change very little by the end of each trial. Obviously, simulations of 100 -msec ISIs require bins of $100 \mathrm{msec}$ or less.

Each trial consisted of 12 bins: CSs and the US were restricted to the first 6 bins; the second 6 bins were allocated to the intertrial interval. Given the value of $\mathrm{k}=.1$ in Equation 3, an intertrial interval of 6 bins was sufficient to preclude associations between events on one trial and those on the next. Unless otherwise specified, the simulations assumed that the CSs occupied the first 3 bins and the US the third bin. The context occupied all 12 bins on every trial.

In the M-S model, parameter values for variations of associative and antiassociative values were: $\theta=0.4$ and $\theta^{\prime}=0.04$. $\theta$ was set 10 times greater than $\theta^{\prime}$ because increments in $\dot{V}$ during the US presentation should overcome decrements in $\dot{V}$ during the absence of the US in order to obtain positive values of $\dot{V}$ (see Figure 1D). Weighting coefficients for computation of components of associability were: $\phi_{\mathrm{US}}=1, \phi_{\mathrm{A}}=.16, \phi_{\mathrm{B}}=.16, \phi_{\mathrm{X}}=.01$, and $\mathrm{c}=0.6$, because the US is presumed to be represented in memory more strongly than the CSs and CSs more strongly than context. c, the rate parameter for changes in $\Delta \alpha$, was set equal to 0.6 in order to yield an adequate rate of change in $\alpha$. Initial values of associability were always selected $\alpha_{X}=0.1, \alpha_{A}=0.5$, and $\alpha_{B}=0.5$, giving an intermediate value in associability to the newly presented CSs and a low associability to the context with the assumption that associabilities are proportional to the relative saliences of CSs and context. Initial values of $V_{A}=V_{B}=V_{X}=0$ and $N_{A}=N_{B}=N_{X}=0$.

Predictions from the M-S model for the present purposes do not depend on the selected parameter values. For instance, changes in values of $\phi$ or $c$ affect the number of trials needed to obtain LI, blocking, and so forth, but not the phenomena in themselves. Changes in the initial associabilities affect the number of trials needed to reach asymptotic values of $\dot{V}$. The same set of parameters was applied to all simulations.

In the S-P-H model, initial $\mathrm{V}$ and $\mathrm{N}$ values were zero in all protocols, with the exception of extinction. Initial $\alpha \mathrm{s}$ were 1 for every CS based on the assumption that associability is maximal for newly presented CSs. Simulation of LI requires a slow variation in $\alpha$ and therefore $\gamma$ was set equal to .9. S was set equal to $1, \beta_{\mathrm{E}}$ equal to .1 , and $\beta_{\mathrm{I}}$ equal to .01 , in order to reach asymptotic level in 10 simulated trials.

As in the M-S model, most predictions do not depend on the selected parameter values. For instance, the only critical parameter is initial $\alpha$ s equal to 1 , in order to obtain LI. Changes in $\gamma$ affect the number of trials needed to obtain LI, but not the phenomenon itself. Changes in $S, \beta_{E}$, and $\beta_{I}$ affect the number of trials needed to reach asymptotic values of $\mathrm{V}$ and $\mathrm{N}$. The same set of parameters was applied to all simulations.

In the simulations, asymptotic values were reached after $10 \mathrm{ac}-$ quisition trials. Therefore, one simulated trial was approximately equivalent to 10 to 20 experimental trials, depending on species and preparation.

Both the M-S and the S-P-H models assume that CR strength is monotonically related to $\Sigma \dot{V}_{\mathrm{j}}$. This mapping rule gives a reasonable approximation to asymptotic behavior.

\section{RESULTS AND DISCUSSION}

\section{Acquisition}

Acquisition of classical conditioning was simulated under simultaneous, forward delay, and trace paradigms with the CS and the US 1 bin in duration. In simultaneous conditioning, the CS and the US were presented in the $1 \mathrm{st}$ bin. In delayed conditioning, the interstimulus interval (ISI) was 1-bin, that is, the CS occupied the 1st bin and the US occupied the 2nd bin. In trace conditioning, the ISIs were 2-, 3-, or 4-bin. In all cases, the context occupied all 12 bins in every trial.

After 10 simulated trials with the M-S model in a delayed conditioning paradigm, the values obtained for the normal case were: $\mathrm{V}=.86, \mathrm{~N}=.05$, and $\dot{\mathrm{V}}=.81$. The same values were obtained for the HL case. The corresponding values from the S-P-H model for the normal case were $\mathrm{V}=.65, \mathrm{~N}=.02$, and $\dot{\mathrm{V}}=.63$. The values obtained for the HL case were $\mathrm{V}=.65, \mathrm{~N}=.01$, and $\dot{\mathrm{V}}=.64$.

Figure 2 shows simulated asymptotic $\dot{V}$ s for both normal and HL cases as a function of ISI obtained with the M-S and the S-P-H models. The simulated data from the M-S and the S-P-H models are similar except for simultaneous and trace conditioning paradigms in HL cases. The S-P-H model predicts higher asymptotic values for the HL cases because the CS can accrue associative value independently of the context.

The simulated data from both models resemble the ISI data obtained from normal animals by Schneiderman and Gormezano (1964) in the rabbit NM preparation. There are no comparable data on simultaneous conditioning for HL animals. Schmaltz and Theios (1972) report faster acquisition in HL rabbits than in controls in delay conditioning with an ISI of $250 \mathrm{msec}$. However, subsequent studies of delay conditioning using longer ISIs (e.g., Berger \& Orr, 1983; Solomon, 1977; Solomon \& Moore, $1975)$ report no difference between HL rabbits and controls either in the rate of acquisition or asymptotic levels of conditioned responding. Both the M-S model and the S-P-H model provided a reasonably accurate rendering of $\mathrm{HL}$ effects in rabbit NM delay conditioning. In trace conditioning with an air-puff US, HL does not affect rate of acquisition (M. M. Patterson, personal communication, 1984; except see Solomon, Vander Schaaf, Thompson, \& Weisz, in press). The M-S model, but not the S-P-H model, provided the better prediction of the of $\mathrm{HL}$ in rabbit NM conditioning.

Simulated acquisition with a $50 \%$ reinforcement schedule was contrasted with $100 \%$ reinforcement in a delay conditioning paradigm in which the CS occupied the first 3 bins and the US, on reinforced trials only, occupied the 
3rd bin. In both cases, the context occupied all 12 bins in every trial. Figure 3 shows simulated asymptotic $\dot{V}$ with $100 \%$ reinforcement (labeled perfectly contingent) and $50 \%$ reinforcement (labeled partially contingent). With both models, $100 \%$ reinforcement resulted in higher asymptotic $\dot{V}$ than $50 \%$ reinforcement in both normal and HL cases. With the M-S model, since $\alpha$ for the context does not decrease in the HL case, the context accrued higher $\dot{V}$; therefore $\alpha$ for the CS did not increase as much as it does in the normal case and, consequently, the CS asymptotic $\dot{V}$ was slightly lower in the HL case than in the normal case under both schedules. In contrast, with both reinforcement schedules, the S-P-H model yielded significantly higher asymptotic $\dot{\mathrm{V}}$ in the HL case than in the normal case, and this occurred because the CS can accrue $\dot{V}$ independently from the context.

Schmajuk and Isaacson (1984) investigated the effect of HL in rats trained in a procedure in which olfactory stimuli were paired with grid shock. Rats were tested for aversion of the olfactory cue associated with the US. Following training, $\mathrm{HL}$ rats showed more aversion to CSs than normals, suggesting that they had acquired a stronger $\mathrm{CR}$. The possibility that $\mathrm{HL}$ animals can achieve higher levels of conditioning than do normals is reinforced by findings of higher performance levels under partial and $100 \%$ reinforcement (Rickert, Lorden, Dawson, Smyly,

\section{MONISITIDH.}
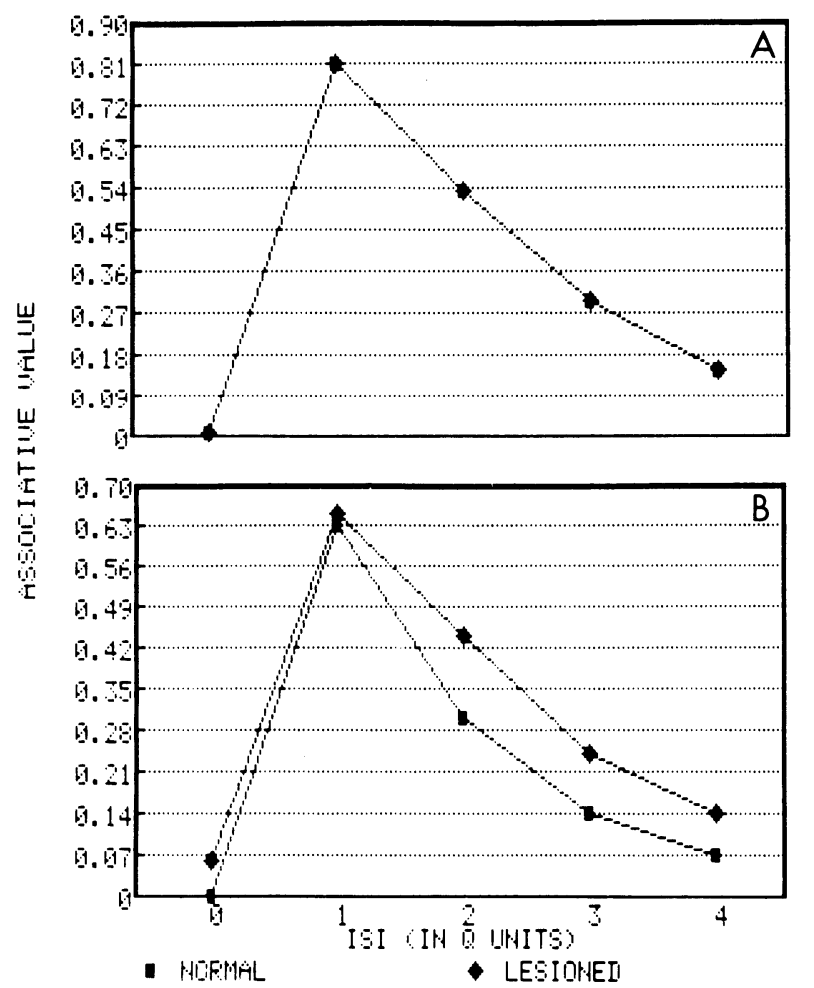

Figure 2. Acquisition. Net associative value of a reinforced $\mathrm{CS}$ for normal and $H L$ cases as a function of the ISI after 10 conditioning trials. Time is expressed in $q$ (optimal conditioning interval) units. Panel A: M-S model. Panel B: S-P-H model.

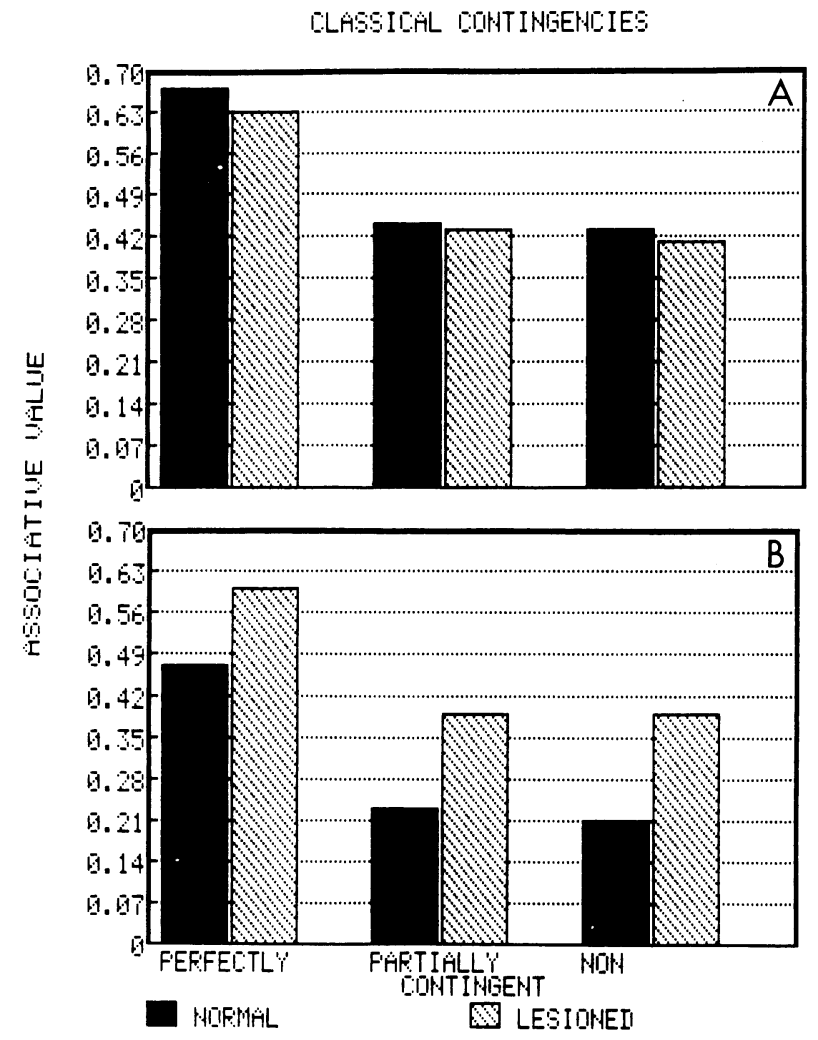

Figure 3. Classical contingencies. Net associative value of a reinforced CS for normal and HL cases after 10 trials under perfect, partial, and zero contingent training. Panel A: M-S model. Panel B: S-P-H model.

\& Callahan, 1979; Schmajuk \& Isaacson, 1984). The results for $50 \%$ reinforcement agree with the simulations from the S-P-H model but differ from those made by the M-S model.

\section{Noncontingent Training}

To produce efficient conditioning, a CS must be a reliable predictor of the US, that is, the US should occur frequently in the presence of the CS but rarely in its absence. The ability of a CS to predict a US can be measured in terms of the contingency between the CS and the US. This contingency is specified according to two conditional probabilities: the probability of receiving the US given the CS $[\mathrm{P}(\mathrm{US} / \mathrm{CS})]$ and the probability of receiving the US given the nonoccurrence of the CS [P(US/nonCS)]. Excitatory conditioning is obtained whenever $\mathrm{P}(\mathrm{US} / \mathrm{CS})$ $>\mathrm{P}(\mathrm{US} /$ nonCS $)$, inhibitory conditioning when $\mathrm{P}(\mathrm{US} / \mathrm{CS})$ $<\mathrm{P}(\mathrm{US} /$ nonCS $)$, and no conditioning when $\mathrm{P}(\mathrm{US} / \mathrm{CS})$ $=\mathrm{P}(\mathrm{US} /$ nonCS) $($ Rescorla, 1968).

For simulations of noncontingent training, four types of trials occurred in succession and the sequence was repeated five times. The four types of trials were as follows: (1) CS followed by US, (2) CS followed by noUS, (3) noCS (context alone) followed by US, and (4) noCS (context alone) followed by noUS. When delivered, the CS occupied the first 3 bins of the trial. When delivered, 
the US occupied the 3 rd bin. In all cases, the context occupied all 12 bins in every trial.

Figure 3 shows asymptotic $\dot{\mathrm{V}}$ for $\mathrm{HL}$ and normal cases under simulated noncontingent training. For the normal case, both models yielded virtually the same asymptotic $\dot{V}$ s under partially contingent (50\% reinforcement in the preceding paragraph) and noncontingent training. Schmajuk and Isaacson (1984) found that noncontingent training $[\mathrm{P}(\mathrm{US} / \mathrm{CS})=\mathrm{P}(\mathrm{US} /$ nonCS $)]$ resulted in lower asymptotic conditioning than did partially contingent training in normal rats. HL rats behaved as do normal rats. For the HL case, both models yielded asymptotic $\dot{V}$ higher than that found by Schmajuk and Isaacson (1984).

In order to encompass Schmajuk and Isaacson's (1984) result, it is necessary that the CS's associability decreases as the $\dot{V}$ of the context increases. In the M-S model, this would occur given a sufficiently high initial $\alpha$ for the context and provided that $\dot{V}$ for the context did not decrease substantially during the ITI period. However, these two conditions cannot be satisfied simultaneously in the model. In the S-P-H model, the CS's associability would decrease provided that $\dot{V}$ for the context did not decrease substantially during the ITI period, a condition that can be satisfied with, for example, a shorter ITI.

\section{Inhibitory Conditioning}

Simulations of inhibitory learning were carried out under two experimental procedures, conditioned inhibition and differential conditioning. CSs occupied the first 3 bins of each trial, and the US, when presented, occupied the 3 rd bin. In both cases, the context occupied all 12 bins in every trial. In conditioned inhibition training, two types of trials were alternated: reinforced trials, which consisted of a single reinforced $\mathrm{CS}(\mathrm{A})$, and nonreinforced trials, which consisted of a compound CS (A and B). Stimulus B was the conditioned inhibitor. After 10 simulated trials, $\dot{\mathrm{V}}$ of B computed with the M-S model was -.15 for the normal case and -.17 for the HL case. The corresponding $\dot{\mathrm{V}}$ s from the S-P-H model were -.20 and 0 , respectively. The S-P-H model predicted no conditioned inhibition for the HL case because $\alpha$ for Stimulus B equals zero to the extent that it depends on only the associative value of Stimulus B.

Solomon (1977) found that conditioned inhibition of the rabbit NM response was not affected by HL. Solomon's (1977) results are in agreement with the M-S model but not with the S-P-H model.

In differential conditioning, training consisted of alternated CS(A)+ and CS(B) - trials. After 10 simulated trials (5 of each type), $\dot{V}$ of CS(B) computed with the M-S model was -.03 in normal cases and -.04 in HL cases. By contrast, the S-P-H model yielded $\dot{V}$ s of -.10 for the normal case and 0 for the HL case.

Micco and Schwartz (1971) investigated differential fear conditioning in rats. The inhibitory properties of CSwere assessed in terms of its effects on an avoidance response. Unlike controls, HL animals failed to show sup- pressed avoidance in the presence of CS- . Berthier and Moore (1980) investigated simple differential conditioning to visual spatial CSs. HL rabbits did not differ from controls in responding to $\mathrm{CS}+$, but they appeared to show greater suppression of response to CS- However, it is not clear that CS- had actually become more inhibitory in HL animals than in controls because summation and retardation tests were not carried out. Micco and Schwartz's (1971) study supports simulations obtained with the S-P-H model but not those obtained with the M-S model.

\section{Extinction}

Ten extinction trials were simulated, with initial values resulting from simulations of 10 reinforced trials in a delay conditioning paradigm in which the CS occupied the 3 first bins and the US occupied the 3 rd bin. The context occupied all 12 bins in every trial. Figure 4 shows that rates of extinction for normal and HL cases differed only slightly in both models.

Extinction of conditioned NM response in rabbits appears to be unaffected by HL (Berger \& Orr, 1983; Schmaltz \& Theios, 1972). However, HL rabbits have been reported to show greater resistance to extinction than normals following reacquisition (Schmaltz \& Theios, 1972). These results are in accordance with the simulation obtained with both models.

\section{EXTINCTION}

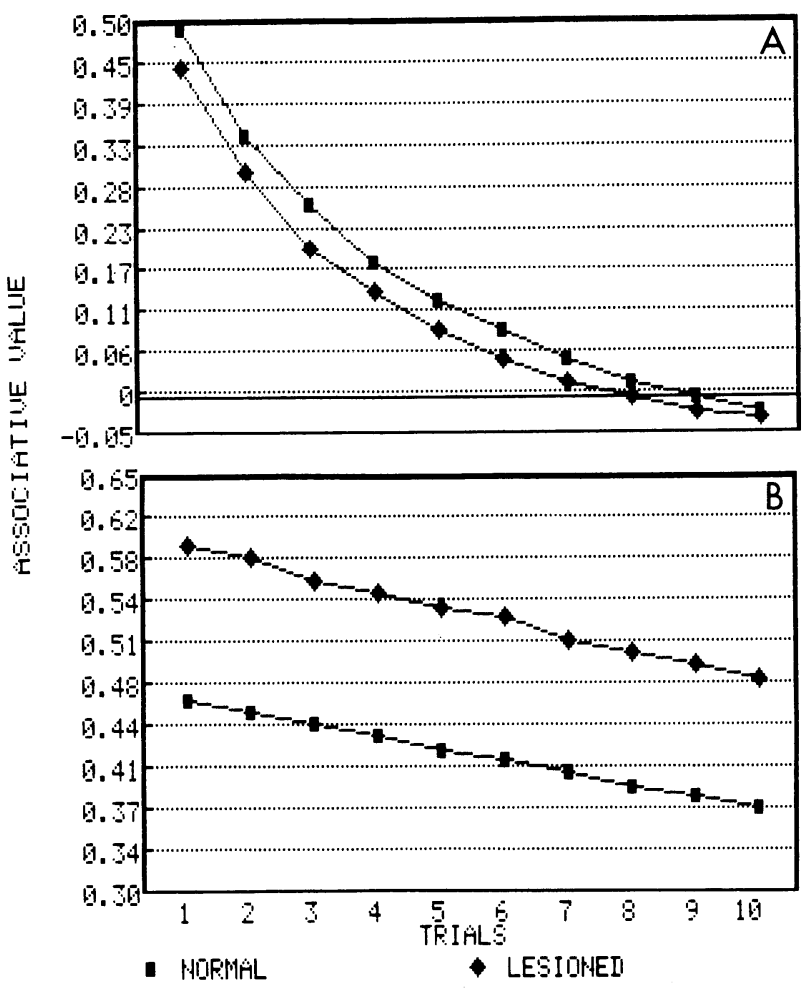

Figure 4. Extinction. Net associative value of a previously reinforced CS for normal and HL cases as a function of trials during extinction. Panel A: M-S model. Panel B: S-P-H model. 


\section{Latent Inhibition}

Latent inhibition (LI) refers to the finding that presenting the CS alone repeatedly before pairing it with the US produces retardation in the acquisition of the $\mathrm{CR}$.

The M-S model makes explicit the effect of various temporal parameters on LI resulting from CS preexposure. For the normal case, the model stipulates that LI is a decreasing function of CS duration and an increasing function of the intertrial interval (ITI) (see Moore \& Stickney, 1980). With a CS of comparatively brief duration, the context becomes the best predictor of the CS, and therefore the CS loses associability and LI occurs. With a CS of comparatively long duration, the CS becomes the better predictor of itself than does the context, and therefore the CS gains associability and LI does not occur. In the HL case, the M-S model does not permit LI because the associability of the preexposed CS cannot decrease.

In the S-P-H model, LI depends only on the number of CS preexposures and not on its duration or the ITI. This model also predicts the absence of LI in the HL case because, even though the CS's associability decreases during preexposure, it is not averaged with the CS's associability on trials on which CS and US are paired.

Figure 5 shows $\dot{V}$ s following a series of 20 CS preexposures (CS occupied first bin) followed by 5 trials on

\section{LATERT IHHIEITIONH}

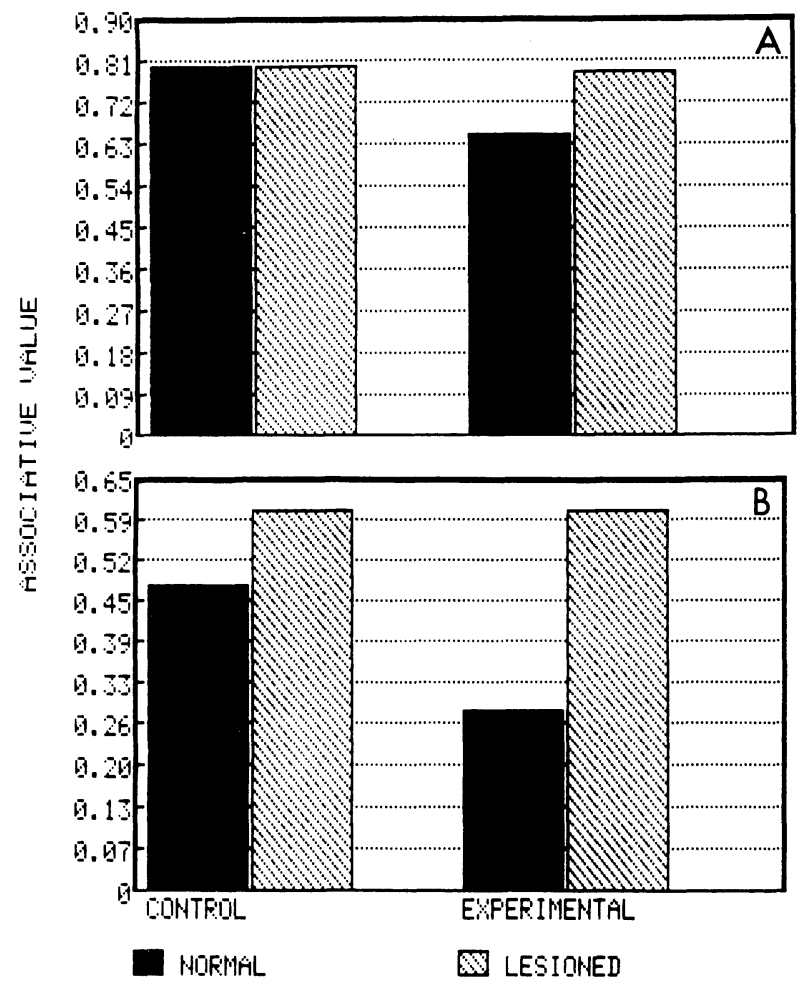

Figure 5. Latent inhibition. Net associative value of a reinforced CS for normal and HL cases in a latent-inhibition paradigm. Experimental groups received 20 trials of CS preexposure and 5 CS reinforced trials. Control groups received 20 trials of preexposure to the context alone and 5 CS-reinforced trials. Panel A: M-S model. Panel B: S-P-H model.

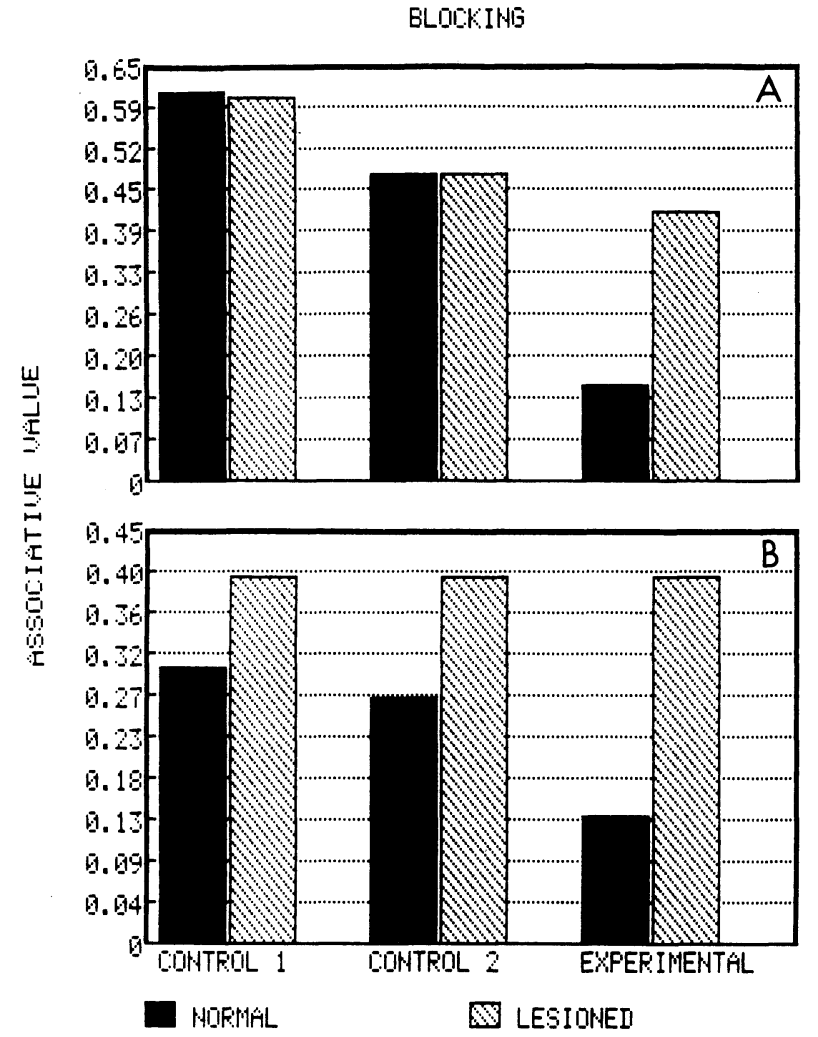

Figure 6. Blocking. Net associative value of $\operatorname{CS}(B)$ for lesioned and normal simulated cases, in a blocking paradigm. Experimental groups received five $\operatorname{CS}(\mathrm{A})+$ trials followed by five $[\mathrm{CS}(\mathrm{A}) \operatorname{CS}(\mathrm{B})]+$ trials. Control 1 groups received five $\mathrm{CS}(\mathrm{B})+$ trials. Control 2 groups received five [CS(A) CS(B)]+ trials. Panel A: M-S model. Panel B: S-P-H model.

which the CS occupied the 1st bin and the US occupied the 2 nd bin. Control cases received 20 context-only trials followed by the 5 CS-US trials. In both cases, the context occupied all 12 bins in every trial. Animals with HL are reported to show impaired LI (MacFarland, Kostas, \& Drew, 1978; Solomon \& Moore, 1975). Consistent with these results, simulated LI was virtually eliminated in the HL case with both models.

\section{Blocking}

In blocking, an animal is first conditioned to a CS (A). This training is followed by conditioning to a compound CS consisting of $\mathrm{A}$ and a second stimulus (B). This procedure results in weaker conditioning to $\mathrm{B}$, as a component of the compound $\mathrm{CS}$, than would occur without the prior conditioning to $\mathrm{A}$.

Figure 6 shows Vंs of normal and HL cases after experimental and control procedures in a blocking paradigm. Experimentals received five trials with one CS (blocker) paired with the US followed by five trials with the same CS and a second (blocked CS) paired with the US, as stipulated under Methods. Controls received either five single-CS trials, in which the designated blocked CS was paired with the US (Control 1 in Figure 6), or five twoCS trials, in which both CSs were presented together and 
paired with the US (Control 2 in Figure 6). Control 2 was subject to mutual overshadowing between the two component CSs; Control 1 provided a baseline for assessing the degree of overshadowing in Control 2. Figure 6 shows that both models simulated blocking in the normal case, because $\dot{V}$ for the designated blocked CS was lower in the experimental condition than in either control condition.

Solomon (1977) found that HL disrupted blocking of the rabbit NM response, and Rickert, Bennett, Lane, and French (1978) reported similar effects of HL on conditioned suppression in rats. By contrast, Garrud et al. (1984) failed to observe deficits in blocking of conditioned suppression in HL animals. Consistent with Rickert et al. (1978) and Solomon (1977), simulations with both models show that HL virtually eliminated blocking. In the M-S model, the designated blocked CS did not lose associability in the HL case and therefore was able to achieve a high $\dot{V}$. In the S-P-H model, the designated blocked CS's associability $\left(\alpha=\left|\lambda_{n}-V_{i}^{n-1}\right|\right)$ was larger in the HL case than in the normal case $\left(\alpha_{i}=\left|\lambda-\Sigma V_{j}^{n-1}\right|\right)$.

Comparing Control 1 with Control 2 in Figure 6A shows that the M-S model yielded mutual overshadowing of the designated blocked CS by the blocker in both the normal and HL cases. HL did not affect mutual overshadowing, because both CSs had the same initial value of associability. They therefore accumulated $\dot{V}$ at the same rate, but without the increase in associability that normally occurs when a single CS is paired with the US. Had the designated blocked CS had a lower initial associability than the blocker, HL would have prevented overshadowing. Figure 6B shows that the S-P-H model resulted in mutual overshadowing of the designated blocked CS by the blocker in the normal case. HL produced greater than normal $\dot{V}$ for the designated blocked CS in both controls, because its associability was not influenced by either the context or the blocker.

Control groups in Solomon's (1977) investigation of blocking of the conditioned NM response provide evidence regarding the effect of HL on mutual overshadowing between two compounded CSs of differential salience. Unlike the case of blocking, HL rabbits showed no deficit in overshadowing. Solomon's (1977) results agree with the simulations obtained with the M-S model but not with those obtained with the S-P-H model.

\section{Overshadowing}

In overshadowing, an animal is conditioned to a compound CS consisting of two stimuli, $A$ and $B$. If $A$ is more salient than B, B becomes weakly conditioned at best, that is, A overshadows B. If A and B are equally salient, mutual overshadowing occurs such that neither A nor B becomes as strongly conditioned as if they had each been paired with the US for an equivalent number of trials. Overshadowing is affected not only by the relative intensities of the two component CSs, but also by their relative contingencies with respect to the US: the better predictor of the US becomes more strongly conditioned than does the poorer predictor.
Overshadowing involves alternating single-CS trials with those consisting of two CSs in a compound. Experimentals received five reinforced trials with one CS (A) alternated with five reinforced trials with A compounded with a second CS (B). Therefore, A was the more consistent of the two predictors of the US, and in this circumstance A should overshadow B in the normal case. As in the blocking experiment, controls received either five single-CS trials in which CS(B) was paired with the US (Control 1 in Figure 7) or five two-CS trials in which both CSs (A and B) were presented together and paired with the US (Control 2 in Figure 7). Figure 7 shows that both models simulated overshadowing in the normal case, because $\dot{V}$ for CS(B) was lower in the experimental condition than in either control condition.

Rickert et al. (1979) investigated overshadowing in a conditioned suppression task in which a tone CS was the better predictor of the US than was a light CS. As expected, normal animals showed greater conditioning to tone than to the light. HL animals showed strong conditioning to both CSs, suggesting a deficit in overshadowing. A deficit in overshadowing between CSs with differential predictive contingencies with respect to the US was also observed by Schmajuk, Spear, and Isaacson

\section{DUEROHAIIOWINIS}
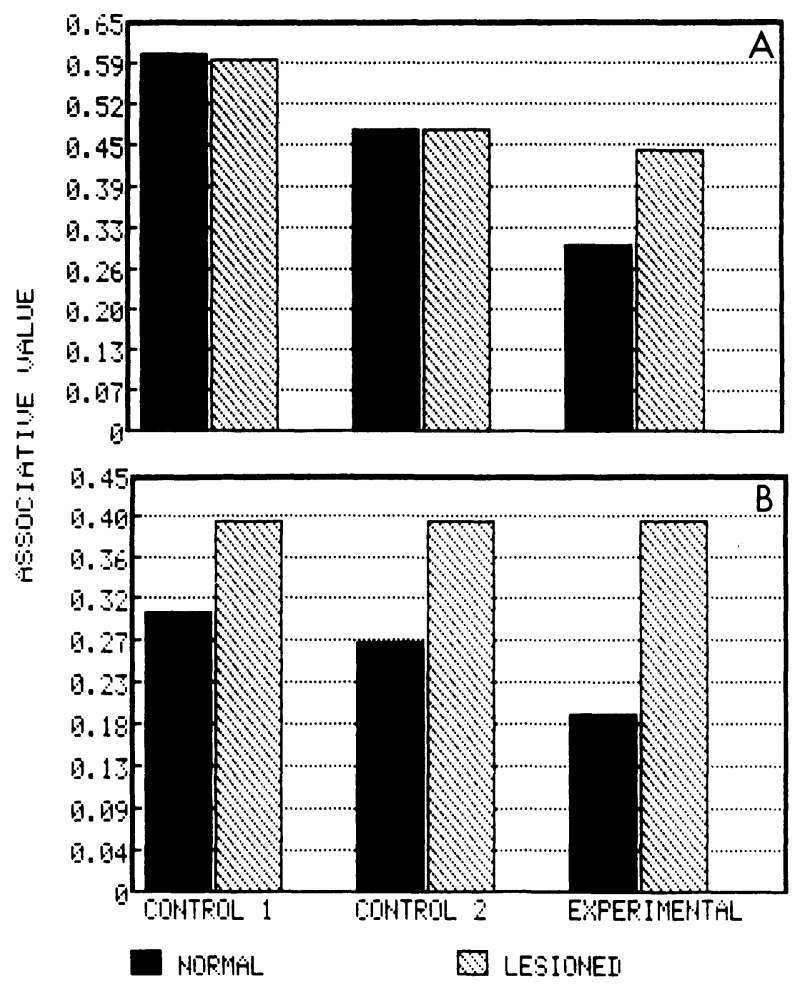

Figure 7. Overshadowing. Net associative value of $\operatorname{CS}(B)$ for lesioned and normal simulated cases, in an overshadowing paradigm. Experimental groups received five trials with $\mathrm{CS}(\mathrm{A})+$ alternated with five trials with $[\mathrm{CS}(\mathrm{A}) \mathrm{CS}(\mathrm{B})]+$. Control 1 groups received five $\mathrm{CS}(B)+$ trials. Control 2 groups received five $[\mathrm{CS}(\mathrm{A}) \mathrm{CS}(\mathrm{B})]+$ trials. Panel A: M-S model. Panel B: S-P-H model. 
(1983). Rats were trained in a simultaneous discrimination problem using both olfactory and visual cues, the first predicting the US better than the second. The olfactory cues overshadowed the visual cues in normal animals but not in HL animals. In contrast to Rickert et al. (1979) and Schmajuk et al. (1983), Garrud et al. (1984) failed to find HL-induced deficits in overshadowing in conditioned suppression when a CS poorly correlated with the US was presented together with a CS highly correlated with the US. This study also failed to observe HL-induced deficits in overshadowing when a CS of weak salience was compounded with a CS of strong salience. Consistent with Rickert et al. (1979) and Schmajuk et al. (1983), simulations with both models indicate that HL virtually eliminated overshadowing. Both models yielded impaired overshadowing in the HL case for the same reasons that they yielded impaired blocking.

\section{Discrimination Reversal}

Figure 8 shows Vs in normal and HL cases after simulated differential conditioning and discrimination reversal. In the differential conditioning phase, five reinforced trials with one CS (A) alternated with five nonreinforced trials with a second CS (B). During reversal, the original nonreinforced CS (B) was reinforced for five trials; these

\section{IIGCFIMINATION FEUEFGAL}

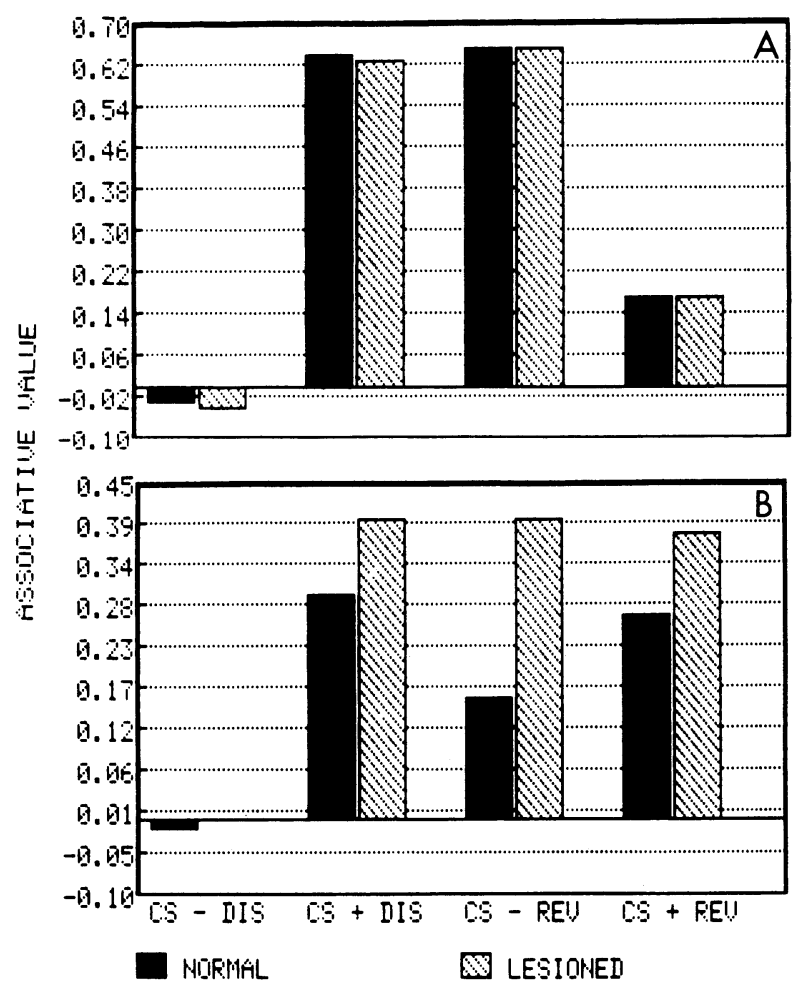

Figure 8. Discrimination reversal. Net associative value of the original CS+ and CS - for lesioned and normal simulated cases, after 10 trials of discrimination (DIS) and 10 trials of reversal (REV) training. Panel A: M-S model. Panel B: S-P-H model. trials alternated with five trials in which CS (A), the reinforced CS in the first phase, was presented without the US.

Simulations with the M-S model are shown in Figure 8A. After differential conditioning in the first phase, Vंs for each CS were virtually the same for normal and HL cases. After differential conditioning, $\dot{V}$ for A (labeled CS+ DIS in Figure 8) was higher than $\dot{V}$ for B (labeled CS- DIS in Figure 8), which became slightly inhibitory. After reversal, $\dot{V}$ for B (labeled CS- REV in Figure 8) increased to approximately the same level achieved by $A$ in Phase 1 . At the same time, $\dot{V}$ for A (labeled CS+ REV in Figure 8) decreased from its Phase 1 level as a consequence of the five nonreinforced trials. After reversal, Vs for each CS were virtually the same for normal and HL cases.

Simulations with the S-P-H model are shown in Figure 8B. After differential conditioning, A attained a higher $\dot{V}$ in the HL case than in the normal case. The $\dot{V}$ for $\mathrm{B}$ became slightly inhibitory in the normal case and zero in the HL case. After reversal in the normal case, $\dot{V}$ for the previously nonreinforced CS, B, increased, but this increase was not accompanied by a corresponding decrease of $\dot{V}$ for the previously reinforced CS, A. In fact, the simulated $\dot{V}$ for $\mathrm{A}$ was higher than that for B following reversal. After reversal in the HL case, Vंs for both $\mathrm{A}$ and $\mathrm{B}$ were higher than in the normal case, and there was only a small difference between them. Doubling the number of reversal trials produced Vंs that more closely resembled those generated with the M-S model in the normal case.

Buchanan and Powell (1980) examined HL effects on acquisition and reversal of discrimination of heart rate and eyeblink conditioning. HL slightly impaired acquisition and greatly impaired reversal of the eyeblink discrimination due to an increased responding to the CS-. Berger and Orr (1983) contrasted HL and control rabbits in twotone differential conditioning and reversal of the rabbit NM response. Although HL did not affect initial differential conditioning, these animals were incapable of suppressing CRs to the original CS+ after it assumed the role of CS-, even following extended training. It would appear that the S-P-H model rendered the more realistic portrayal of the experimental data.

\section{Sensory Preconditioning}

Port and Patterson (1984) report disruption of sensory preconditioning of the NM response in rabbits with fimbrial lesions. The models considered in this report can be applied to sensory preconditioning only with additional assumptions, which are discussed below.

\section{Conditional Discrimination}

Ross, Orr, Holland, and Berger (1984) investigated HL effects on conditional responding in a serial featurepositive discrimination task. In this task, a light preceded a tone CS on reinforced trials but not on nonreinforced trials. The response to the tone was a head jerk. HL selec- 
tively disrupted acquisition and retention of the discrimination between the tone preceded by a light and tone alone. Acquisition and retention of a nonconditional discrimination between a click and white noise were not affected by HL.

Neither model can simulate conditional discrimination with the conditional cue preceding the nominal CS in the normal case. In the normal case, the nominal CS, having higher $\dot{V}$ than the conditional cue, because of its more favorable temporal relation to the US, would come to overshadow the conditional cue. No conditional discrimination could occur because, since the conditional cue can accrue only a small $\dot{V}, C R$ strength is determined mainly by the $\dot{V}$ of the nominal CS, and discrimination between reinforced and nonreinforced trials would be difficult.

However, both models can simulate conditional discrimination with simultaneous presentation of nominal CS and conditional cue in the normal case. Simulations consisted of alternated presentations of the conditional cue and the CS in the presence of the US, and the CS alone. With both models, the CS acquires a smaller $\dot{V}$ than the conditional cue because it is exposed to nonreinforced trials, and therefore the cue overshadows the CS. Conditional discrimination occurs because, since the CS accrues only a small $\dot{V}, \mathrm{CR}$ strength is determined mostly by the conditional cue. In the HL case, since the conditional cue does not overshadow the CS, conditional cue and nominal CS elicit a CR, and discrimination is not possible. These results are in accordance with Ross et al.'s (1984) data.

\section{Summary}

Table 1 compares the results of the simulation experiments with the experimental data. When a simulation result did not match at least one experimental result, the result was labeled as incorrect. The M-S model did not realistically simulate the behavior of normal animals in

Table 1

Simulations of the M-S and S-P-H Models Compared With the Experimental Results of Some Classical Conditioning Paradigms After HL

\begin{tabular}{|c|c|c|c|}
\hline \multirow[b]{2}{*}{ Paradigm } & \multirow{2}{*}{$\begin{array}{l}\text { Observed } \\
\text { HL Effect }\end{array}$} & \multicolumn{2}{|c|}{$\begin{array}{c}\text { Simulated HL Effec } \\
\text { with Model }\end{array}$} \\
\hline & & M-S & S-P-H \\
\hline Simultaneous Conditioning & $\mathrm{X}$ & 0 & + \\
\hline Delay Conditioning & $0,+$ & 0 & + \\
\hline Trace Conditioning & 0 & 0 & $+b$ \\
\hline Partial Reinforcement & + & $0 \mathrm{~b}$ & + \\
\hline Noncontingent Training & 0 & $0 \mathrm{a}, \mathrm{b}$ & $+a, b$ \\
\hline \multicolumn{4}{|l|}{ Inhibitory Conditioning } \\
\hline a. Conditioned Inhibition & 0 & 0 & $-b$ \\
\hline b. Differential Conditioning & - & $0 \mathrm{~b}$ & - \\
\hline Extinction & 0 & 0 & 0 \\
\hline Latent Inhibition & - & - & - \\
\hline Blocking &,- 0 & - & - \\
\hline Overshadowing &,- 0 & - & - \\
\hline Discrimination Reversal & - & $0 \mathrm{~b}$ & 0 \\
\hline
\end{tabular}

Note $-+=$ facilitation; $-=$ deficit $0=$ no effect; $X=$ no available data; $a=$ the model fails to describe accurately the normal case; $b=$ the model fails to describe accurately the HL case. noncontingent training. The model also had problems simulating the behavior of HL animals under partial reinforcement, noncontingent training, differential conditioning, and discrimination reversal. The S-P-H model had difficulties describing the behavior of normal animals in noncontingent training. The model also had problems describing the behavior of HL animals in trace conditioning, noncontingent training, and conditioned inhibition.

As did the original M-S model, the revised version considered in this paper was able to describe the effects of HL on blocking and LI. In addition, the model successfully described HL effects under delay conditioning, trace conditioning, conditioned inhibition, extinction, and overshadowing. The S-P-H model successfully described HL effects under delayed conditioning, partial reinforcement, inhibition following differential conditioning, extinction, latent inhibition, blocking, and overshadowing.

The two models differed in their descriptions of HL effects in trace conditioning, partial reinforcement, conditioned inhibition, inhibition following differential conditioning, and discrimination reversal, the M-S model performing better in trace conditioning and conditioned inhibition and the S-P-H model performing better in partial reinforcement, inhibition following differential conditioning, and discrimination reversal.

\section{GENERAL DISCUSSION}

The thesis of this article is that the effect of HL in classical conditioning can be represented by modifications in the computation of variables defined in attentional models of learning. In the M-S model, HL animals are unable to reduce the associability of CSs. In the S-P-H model, computations of a CS's associability by HL animals are not influenced by other CSs or by its associability on previous occasions.

The M-S model has a total of nine parameters to be set: $\theta, \theta^{\prime}, \alpha_{\mathrm{X}}, \alpha_{\mathrm{CS}}, \phi_{\mathrm{US}}, \phi_{\mathrm{CS}}, \phi_{\mathrm{X}}, \mathrm{c}$, and k. The S-P-H model has only six parameters to be fixed: $\mathrm{S}, \beta_{\mathrm{E}}, \beta_{\mathrm{I}}, \alpha, \gamma$, and $\mathrm{k}$. In this sense, the S-P-H model seems to be more "parameter efficient" than its counterpart. Very few parameter values seem to be critical in determining the predictions made by the models. In the M-S model, changes in values of $\phi$ or $c$ affect the number of trials needed to obtain LI, blocking, and so forth, but not the phenomena in themselves. Changes in initial $\alpha$ affect the number of trials needed to reach asymptotic values of $\mathrm{V}$ and $\mathrm{N}$. In the S-P-H model, the only critical parameter is initial $\alpha$ s equal to 1 , in order to obtain LI.

Both models successfully described 12 different classical conditioning paradigms, failing only in the noncontingent training case, with the same set of parameters applied to every protocol. Both models also describe a considerable number of reported effects of HL in classical conditioning with the same set of parameters employed to describe normal behavior. In both the normal and $\mathrm{HL}$ cases, the models allow simulation of all possible temporal combinations among stimuli. 
The M-S model failed to simulate the behavior of $\mathrm{HL}$ animals under partial reinforcement, noncontingent training, inhibitory conditioning following differential conditioning, and discrimination reversal. The S-P-H model failed to simulate the behavior of $\mathrm{HL}$ animals under trace conditioning, noncontingent training, and conditioned inhibition. The S-P-H model predicts higher asymptotic responding in delay conditioning for HL than for normal cases. This prediction finds support in an odor preference task based on classical conditioning (Schmajuk \& Isaacson, 1984), but it only partially agrees with the rabbit NM literature. In the latter case, Schmaltz and Theios (1972) report that even though HL rabbits acquired the CR more rapidly than normals, asymptotic levels of responding were not affected in delay conditioning with a $250-\mathrm{msec}$ ISI. Subsequent studies of delay conditioning using longer ISIs report no difference in rate of acquisition or asymptotic levels of responding (e.g., Berger \& Orr, 1983; Solomon, 1977; Solomon \& Moore, 1975). However, the higher than normal asymptotic responding generated by the S-P-H model for the HL case might be supported by Port, Mikhail, and Patterson's (1985) data, which show that, with a $150-\mathrm{msec}$ ISI, HL rabbits show faster acquisition and a higher rate of responding than normal animals do.

Failure to simulate all the classical conditioning paradigms included in the present paper may be a consequence of the variety of species and preparations the models were applied to. For instance, when limited to the HL data from rabbit NM conditioning, the only serious shortcoming of the M-S model is its failure to simulate Berger and Orr's (1983) data on discrimination reversal.

Table 1 makes apparent some inconsistencies in the HL literature. This lack of replicability of the empirical results poses serious difficulties in determining the accuracy of the models. However, it might be valuable to develop models in areas in which empirical results are still in conflict because when the models point out independent variables that are important in determining the magnitude of effects of HL. For both the M-S and the S-P-H models, HL effects will be clearly manifested in those paradigms in which the US is differentially predicted by different CSs.

The most serious shortcoming of the M-S model is its failure to simulate the impairment in discrimination reversal in HL animals reported by Berger and Orr (1983). These authors discuss an account of their data in terms of Solomon and Moore's (1975) theory that the hippocampus "tunes out" irrelevant stimuli. This tuning-out hypothesis differs fundamentally from the portrayal of hippocampal function in the M-S model. Solomon and Moore assumed that the hippocampus allows the animals to ignore irrelevant CSs, by gating them out, so that they cannot control behavior. In the M-S model, the hippocampus decreases a CS's associability so that it does not acquire control over behavior. Once acquired, however, the CSUS relationship maintains control over conditioned behavior until inhibitory processes intervene as a consequence of nonreinforcement. In the HL case, nonrein- forcement of the previously reinforced CS leads to a decrease in the strength of the CS-US relationship because the CS's associability cannot decrease. Conditioned responding can be maintained at a high level in the face of nonreinforcement only if the associability parameter falls quickly to zero. This rapid decrease in associability is not allowed for the HL case under the M-S model.

Neither model considered here could be applied to the sensory preconditioning data of Port and Patterson (1984). However, as a network model, the M-S model includes CS-CS and CS-US associations that might be used for this purpose. Networks with interconnected CS-CS and CSUS nodes would allow simulations of sensory preconditioning. This sort of network implies a "computational cognitive map" that encompasses sensory conditioning phenomena, including higher order conditioning, in a natural way (see Moore, 1979b). A similar network approach with the S-P-H model also has the potential for encompassing these phenomena.

Moore (1979a) proposed a neural model of classical conditioning in which the hippocampus receives an "efference copy" of the CR from the brainstem neurons involved in generating the overt behavior (see Moore \& Solomon, 1984). The hippocampus presumably uses this premature image of the CR to aid in tuning out irrelevant CSs. The efference copies can be regarded as the V́s generated by Equation 3. The version of the M-S model considered in this report uses Vs instead of Vs to compute changes in associability, as in Equations 7 and 8. Computer simulations in which Vंs are substituted for Vs in these equations yield results similar to those presented in this paper.

The S-P-H model is related to neural models that assume that the hippocampus compares actual and predicted events (e.g., Adey, 1966; Gray, 1982; Kornhuber, 1973; Smythies, 1966; Vinogradova, 1975). According to Gray (1982), for example, when actual and predicted events are the same, behavior and attention are unchanged; when a mismatch is detected, the hippocampus inhibits the current behavior and increases attention. This increase in attention is similar to that predicted by the S-P-H model when the predicted event, represented by the variable $\dot{V}$, differs from the actual event, represented by the variable $\lambda$.

\section{REFERENCES}

ADEY, W. R. (1966). Neurophysiological correlates of information transaction and storage in brain tissue. In E. Stellar \& J. M. Sprague (Eds.), Progress in physiological psychology (Vol. 1). New York: Academic Press.

BERGER, T. W., \& ORR, W. B. (1983). Hippocampectomy selectively disrupts discrimination reversal conditioning of the rabbit nictitating membrane response. Behavioural Brain Research, 8, 49-68.

Berthier, N. E., \& Moore, J. W. (1980). Spatial differential conditioning of the nictitating membrane response in hippocampectomized rabbits. Physiological Psychology, 8, 451-454.

Buchanan, S. L., \& Powell, D. A. (1980). Divergencies in Pavlovian conditioned heart rate and eyeblink responses produced by hippocampectomy in the rabbit (Oryctolagus cuniculus). Behavioral \& Neural Biology, 30, 20-38.

Douglas, R. (1972). Pavlovian conditioning and the brain. In R. A. 
Boakes \& M. S. Halliday (Eds.), Inhibition and learning. London: Academic Press.

Douglas, R., \& Pribram, K. H. (1966). Learning and limbic lesions. Neuropsychologia, 4, 197-220.

Garrud, P., Rawlins, J. N. P., Mackintosh, N. J., Goodal, G., Cotton, M. M., \& Feldon, J. (1984). Successful overshadowing and blocking in hippocampectomized rats. Behavioural Brain Research, 12, 39-53.

Grastyan, E., Lissak, K., Madarasz, I., \& Donhoffer, H. (1959). Hippocampal electrical activity during the development of conditioned reflexes. Electroencephalography \& Clinical Neurophysiology, 11, 409-430.

GraY, J. A. (1982). Multiple book review of the neuropsychology of anxiety: An inquiry into the functions of the septo-hippocampal system. Behavioral \& Brain Sciences, 5, 469-534.

KAYE, H., \& PeArCe, J. M. (1984). The strength of the orienting response during Pavlovian conditioning. Journal of Experimental Psychology: Animal Behavior Processes, 10, 90-109.

Kimble, D. P. (1968). Hippocampus and internal inhibition. Psychological Bulletin, 70, 285-295.

KoRNHUBER, H. H. (1973). Neural control of input into long term memory: Limbic system and amnestic syndrome in man. In H. P. Zippel (Ed.), Memory and transfer of information. New York: Plenum Press.

MacFarland, D. J., Kostas, J., \& Drew, W. G. (1978). Dorsal hippocampal lesions: Effects of preconditioning CS preexposure on flavor aversion. Behavioral Biology, 2, 398-404.

MaCKINTOSH, N. J. (1975). A theory of attention: Variations in the associability of stimuli with reinforcer. Psychological Review, 82, 276-298.

Micco, D. J., \& Schwartz, M. (1971). Effects of hippocampal lesions upon the development of Pavlovian internal inhibition in rats. Journal of Comparative \& Physiological Psychology, 76, 371-377.

Moore, J. W. (1979a). Brain processes and conditioning. In A. Dickinson \& R. A. Boakes (Eds.), Mechanisms of learning and behavior. Hillsdale, NJ: Erlbaum.

MOORE, J. W. (1979b). Information processing in space-time by the hippocampus. Physiological Psychology, 7, 224-232.

Moore, J. W., \& Solomon, P. R. (1984). Forebrain-brain stem interaction: Conditioning and the hippocampus. In L. R. Squire \& N. Butters (Eds.), Neuropsychology of memory. New York: Guilford Press.

Moore, J. W., \& STICKNEY, K. J. (1980). Formation of attentionalassociative networks in real time: Role of the hippocampus and implications for conditioning. Physiological Psychology, 8, 207-217.

MOORE, J. W., \& STICKNEY, K. J. (1982). Goal tracking in attentionalassociative networks: Spatial learning and the hippocampus. Physiological Psychology, 10, 202-208.

MoORE, J. W., \& STICKNEY, K. J. (1985). Antiassociations: Conditioned inhibition in attentional-associative networks. In R. R. Miller \& N. E. Spear (Eds.), Information processing in animals: Conditioned inhibition. Hillsdale, NJ: Erlbaum.

Pearce, J. M., \& Hall, G. (1980). A model for Pavlovian learning: Variations in the effectiveness of conditioned but not of unconditioned stimuli. Psychological Review, 87, 532-552.

Pearce, J. M., Kaye, H., \& Hall, G. (1982). Predictive accuracy and stimulus associability: Development of a model of Pavlovian learning. In M. Commons, R. Herrstein, \& A. R. Wagner (Eds.), Quantitative analysis of behavior (Vol. 3). Cambridge, MA: Ballinger.

Port, R. L., Mikhail, A. A., \& Patterson, M. M. (1985). Differential effects of hippocampectomy on classically conditioned rabbit nictitating membrane response related to interstimulus interval. Behavioral Neuroscience, 99, 200-208.

Port, R. L., \& Patterson, M. M. (1984). Fimbrial lesions and sensory preconditioning. Behavioral Neuroscience, 98, 584-589.

Pribram, K. H., \& IsAaCson, R. L. (1975). Summary. In R. L. Isaacson \& K. H. Pribram (Eds.), The hippocampus. New York: Plenum Press.

Rescorla, R. A. (1968). Probability of shock in the presence and absence of shock in fear conditioning. Journal of Comparative \& Physiological Psychology, 66, 1-5.

Rickert, E. J., Bennett, T. L., LANe, P., \& French, J. (1978). Hippocampectomy and the attenuation of blocking. Behavioral Biology, 22, 147-160.

Rickert, E. J., Lorden, J. F., Dawson, R., Smyly, E., \& CallaHAN, M. F. (1979). Stimulus processing and stimulus selection in rats with hippocampal lesions. Behavioral \& Neural Biology, 27, 454-465.

Ross, R. T., OrR, W. B., Holland, P. C., \& Berger, T. W. (1984). Hippocampectomy disrupts acquisition and retention of learned conditional responding. Behavioral Neuroscience, 98, 211-225.

SchmajuK, N. A. (1984a). A model for the effects of the hippocampal lesions on Pavlovian conditioning. Abstracts of the 14th Annual Meeting of the Society for Neuroscience, 10, 124.

Schmajuk, N. A. (1984b). Psychological theories of the hippocampal function. Physiological Psychology, 12, 166-183.

SChmajuk, N. A., \& IsaACSON, R. L. (1984). Classical contingencies in rats with hippocampal lesions. Physiology \& Behavior, 33, 889-894.

Schmajuk, N. A., Spear, N. E., \& IsaAcson, R. L. (1983). Absence of overshadowing in rats with hippocampal lesions. Physiological Psychology, 11, 59-62.

Schmaltz, L. W., \& Theios, J. (1972). Acquisition and extinction of a classically conditioned response in hippocampectomized rabbits (Oryctolagus cuniculus). Journal of Comparative \& Physiological Psychology, 79, 328-333.

Schneiderman, N., \& Gormezano, I. (1964). Conditioning of the nictitating membrane response of the rabbit as a function of the CS-US interval. Journal of Comparative \& Physiological Psychology, 57, 188-195.

SmythIES, J. R. (1966). Brain mechanisms and behavior. New York: Academic Press.

Solomon, P. R. (1977). Role of the hippocampus in blocking and conditioned inhibition of rabbit's nictitating membrane response. Journal of Comparative \& Physiological Psychology, 91, 407-417.

Solomon, P. R. (1979). Temporal versus spatial information processing theories of the hippocampal function. Psychological Bulletin, 86, 1272-1279.

Solomon, P. R., \& Moore, J. W. (1975). Latent inhibition and stimulus generalization of the classically conditioned nictitating membrane response in rabbits (Orytolagus cuniculus) following dorsal hippocampal ablation. Journal of Comparative \& Physiological Psychology, 89, 1192-1203.

Solomon, P. R., Vander SchaAf, E. R., Thompson, R. F., \& Weisz, D. J. (in press). Hippocampus and trace conditioning of the rabbit's classically conditioned nictitating membrane response. Behavioral Neuroscience.

VINOGRADOVA, O. S. (1975). Functional organization of the limbic system in the process of registration of information: Facts and hypotheses. In R. L. Isaacson \& K. H. Pribram (Eds.), The hippocampus. New York: Plenum Press.

(Manuscript received December 15, 1984; revision accepted for publication December 23, 1985.) 